\title{
Sistem Pemantauan Kantuk Menggunakan Instrumentasi Elektrokardiografi dan Visual Haar Classifier pada Pengemudi
}

\author{
Christian Sanjaya, Rachmad Setiawan, dan Nada Fitrieyatul Hikmah \\ Departemen Teknik Biomedik, Institut Teknologi Sepuluh Nopember (ITS) \\ e-mail: rachmad@ee.its.ac.id
}

\begin{abstract}
Abstrak-Menurut data dari Polisi Lalu Lintas (Polantas) pada tahun 2013 menunjukkan bahwa selama periode tahun 2012 dan 2013 angka kecelakaan lalu lintas yang terjadi di Indonesia cenderung menurun, tetapi angka jumlah kecelakaan yang terjadi masih tergolong tinggi jika dibandingkan dengan negara lain. Data tersebut menunjukkan bahwa kantuk pada pengemudi merupakan penyebab kedua terbesar terjadinya kecelakaan lalu lintas. Oleh karena itu dibutuhkan sebuah sistem yang mampu mendeteksi kantuk. Keadaan kantuk dapat dideteksi dengan memonitor kondisi pengemudi dengan menggunakan dua metode pendekatan yaitu pengambilan sinyal biomedis dan menggunakan teknik visual. Salah satu metode pengambilan sinyal biomedis menggunakan elektrokardiograf (EKG) dan visual menggunakan kamera. EKG merupakan alat yang digunakan untuk merekam sinyal jantung. Perancangan instrumentasi EKG menggunakan surface electrode yang dipasang menggunakan metode segitiga eithoven. Instrumentasi EKG terdiri dari penguat instrumentasi yang menggunakan IC AD620 dan melewati filter low pass dengan frekuensi cutoff $0.05 \mathrm{~Hz}$ dan filter high pass dengan cutoff 50Hz. Sinyal EKG akan dikirimkan melalui komunikasi serial ke miniPC. Berdasarkan data dapat diperoleh detak jantung dan rasio LF/HF. Penggunaan satu modalitas tidak cukup untuk menyatakan kondisi dari pengemudi, sehingga perlu ditambahkan metode visual haar classifier untuk mendeteksi kantuk. Perancangan metode visual menggunakan kamera untuk mengambil data frame. Data frame pertama video berupa height dari kelopak mata sebagai threshold. Threshold digunakan sebagai pembanding dengan height frame ke-n untuk mengklasifikasikan kondisi pengemudi sebagai parameter kedua. Penggabungan kedua parameter menggunakan metode if then rule. Melalui pengujian dengan lima subjek didapatkan bahwa sistem pemantauan kantuk menggunakan instrumentasi EKG dan visual haar classifier dapat mendeteksi kantuk satu dari lima subjek yang diuji.
\end{abstract}

Kata Kunci-Elektrokardiografi, Haar Classifier, Heart Rate Variability, Instrumentasi, Kantuk, Visua.l

\section{PENDAHULUAN}

$\mathrm{D}$ ATA dari Badan Pusat Statistik (BPS) pada tahun 2017 menunjukan tingkat penggunaan kendaraan bermotor khususnya mobil penumpang di Indonesia selama 64 tahun terakhir mengalami pertumbuhan [1]. Peningkatan jumlah kendaraan bermotor dapat memberikan dampak negatif yang diberikan salah satunya yaitu naiknya angka kecelakaan lalu lintas. Meskipun, menurut data dari Polisi Lalu Lintas (Polantas) pada tahun 2013 menunjukan bahwa selama periode tahun 2012 dan 2013 angka kecelakaan lalu lintas yang terjadi di Indonesia menurun, tetapi angka jumlah kecelakaan yang terjadi masih tergolong tinggi jika dibandingkan dengan negara lain [2]. Data tersebut

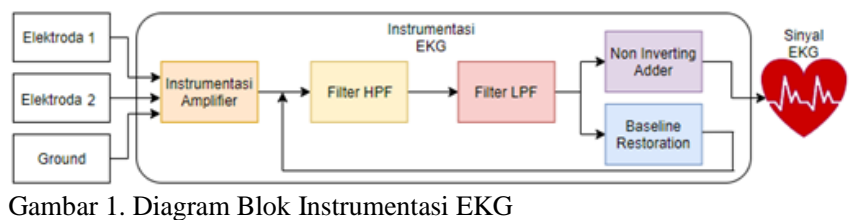

menunjukkan bahwa penyebab kecelakaan lalu lintas paling besar yang ketiga yaitu pengemudi dalam keadaan mengatuk.

Keadaan mengantuk tersebut dapat dideteksi dengan memonitor kodisi dari pengemudi dengan menggunakan dua metode pendekatan yaitu dengan pengambilan sinyal biomedis dan menggunakan teknik visual dengan menggunakan kamera. Sistem yang banyak dikembangkan sampai saat ini hanya menggunakan satu dari kedua metode tersebut. Salah satu contoh metode yang paling banyak digunakan dengan pendekatan pengambilan sinyal biomedis yaitu dengan menggunakan Elektrokardiograf (EKG). Pada metode pengambilan sinyal EKG menggunakan elektroda "fixed-on-body" dimana elektroda tersebut membutuhkan gel $\mathrm{AgCl}$ yang berfungsi sebagai conductive contact. Elektroda ini dapat menghasilkan sinyal jantung dengan kualitas baik. Pada penelitian sebelumnya, hasil deteksi kantuk dengan menggunakan EKG dengan analisa RR Interval (RRI) pada subjek, dengan hasil yang didapatkan memiliki nilai keberhasilan rata-rata penghitungan sebesar 87,5\% [3]. Sedangkan, pada penelitian sistem peringatan dan deteksi lelah pada pengemudi menggunakan Haar classifiers menunjukkan persentase akurasi yang dihasilkan sebesar $89 \%$ [4].

Berdasarkan penelitian sebelumnya maka diperlukan sebuah sistem yang mampu mendeteksi kantuk pada pengemudi mobil tanpa mengurangi tingkat kenyamanan mengemudi dengan menggabungkan dua metode pendekatan. Sehingga, diusulkan sebuah penelitian dengan judul "Sistem Pemantauan Kantuk Menggunakan Instrumentasi Elektrokardiografi dan Visual Haar Classifier pada Pengemudi." Pada penelitian ini akan dirancang sistem yang dapat mendeteksi kantuk pada pengendara mobil dengan menggunakan metode analisa Heart Rate Variability (HRV) dari sinyal EKG dalam fungsi frekuensi serta visual dengan menggunakan metode haar classifier.

\section{PERANCANGAN SISTEM}

Peracangan sistem untuk mendeteksi kantuk dilakukan dengan dua tahap dapat dilihat pada gambar diagram blok sistem keseluruhan pada Gambar 2. Tahap pertama untuk mengolah data instrumentasi EKG dapat dilihat pada Gambar 1, sinyal aktivitas jantung diperoleh dari tubuh melalui 


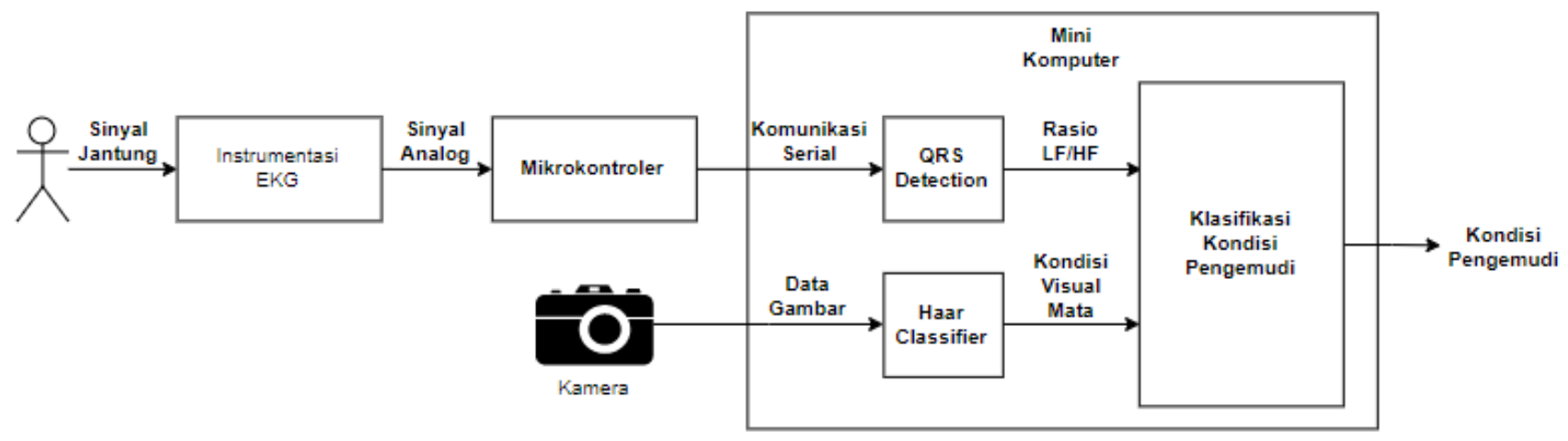

Gambar 2. Diagram Blok Sistem Keseluruhan

elektroda yang dipasangkan menggunakan metode Einthoven, sinyal yang ditangkap akan dikuatkan dan difilter untuk menghilangkan informasi sinyal yang tidak dibutuhkan. Selain itu, untuk menjaga sinyal agar tetap stabil maka ditambahkan rangkaian baseline restoration. Selanjutnya sinyal dilewatkan pada rangkaian non inverting adder untuk menaikkan tegangan agar dapat terbaca oleh mikrokontroler. Tahap kedua yaitu proses komputasi data gambar. Data gambar yang ditangkap oleh kamera akan diolah dengan menggunakan algoritma haar classifier. Data sinyal EKG yang sudah terfilter dan data gambar yang ditangkap masing-masing akan diolah secara digital pada miniPC. Data sinyal EKG akan diolah menggunakan $Q R S$ Detection Pan Tompkins untuk mendapatkan heart rate yang kemudian dianalisa dalam domain frekuensi untuk mendapatkan nilai rasio $\mathrm{LF} / \mathrm{HF}$ yang menjadi parameter untuk menentukan kondisi kantuk. Data gambar yang ditangkap oleh kamera akan diolah dengan algoritma haar classifier dengan parameter rasio besarnya eyelid untuk menentukan kondisi kantuk. Kemudian kedua sistem tersebut diintegrasikan menggunakan algoritma if-then rules.

\section{A. Sadapan}

Sadapan atau lead pada EKG merupakan konduktor yang dipasang di permukaan tubuh manusia untuk merekam aktivitas kelistrikan jantung dalam elektrokardiogram. Setiap sadapan menghasilkan perbedaan potensial yang menjadi sinyal aktivitas kelistrikan jantung sesuai dengan posisinya terhadap jantung. Secara umum, sadapan jantung dapat dibagi menjadi sadapan ekstrimitas dan prekordial. Karena kompleksitas otot jantung, maka untuk EKG diagnosa standar digunakan 12 sadapan dengan tujuan memberikan gambaran multidimensi atau menyeluruh terhadap sinyal jantung dan otot jantung yang menghasilkan sinyal tersebut. Namun untuk monitoring secara umum dapat digunakan elektroda dengan tiga sadapan ekstrimitas standar. Sadapan ini menggunakan metode segitiga Einthoven dengan tiga buah sadapan ekstremitas standar, yaitu lead I, II, dan III, yang dapat dilihat pada Gambar 3. Sinyal EKG direkam dengan bantuan elektroda yang terpasang pada tiga titik tubuh, yaitu Right Arm (RA), Left Arm (LA), dan Left Leg (LL) sesuai dengan aturan segitiga Einthoven. Sadapan I merekam beda potensial antara tangan kanan (RA) yang bermuatan negatif dengan tangan kiri yang bermuatan positif dengan sudut orientasi $0^{\circ}$. Sadapan II merekam beda potensial antara tangan kanan yang bermuatan negatif dengan kaki kiri (LF) yang bermuatan positif dengan sudut orientasi $60^{\circ}$. Sadapan

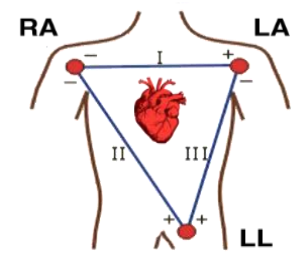

Gambar 3. Segitiga Einthoven

III merekam beda potensial antara tangan kiri (LA) yang bermuatan negatif dengan kaki kiri yang bermuatan positif dengan sudut orientasi $120^{\circ}$.

\section{B. Penguat Instrumentasi}

Rangkaian penguat instrumentasi terdiri atas 4 bagian utama yaitu low pass filter untuk mengurangi efek gain bandwidth rangkaian op amp, rangkiana proteksi melindungi rangkaian dari tegangan tinggi, rangkaian penguat menggunakan AD620 dan rangkaian drive right leg yang berfungsi memberikan feedback. Nilai penguatan dari AD620 bisa didapatkan dengan memvariaskan nilai $R_{G}$, seperti pada Persamaan (1).

$$
\text { Gain }=\frac{49,4 k \Omega}{R_{G}}+1
$$

\section{Filter}

Filter digunakan untuk menghilangkan frekuensi sinyal yang tidak dibutuhkan. Filter yang digunakan antara lain low pass filter dan high pass filter dengan frekuensi cut-off dari masing-masing filter sebesar $0,5 \mathrm{~Hz}$ dan $50 \mathrm{~Hz}$.

\section{Baseline Restoration}

Baseline restoration digunakan untuk menstabilkan sinyal akibat dari pergerakan subjek, interferensi sinyal dari lingungan, dan berbagai faktor lainnya.

\section{E. Non Inverting Adder}

Rangkaian Non Inverting Adder bertujuan untuk menaikkan sinyal EKG sehingga range dari sinyal yang tadinya negatif menjadi positif dan dapat terbaca oleh mikrokontroler.

\section{F. QRS Pan Tompkins}

Suatu detektor QRS umumnya melalui beberapa tahapan. Hampir seluruh algoritma kompleks QRS menggunakan filter untuk menghilangkan komponen gelombang lain yang tidak diinginkan. Pada umumnya digunakan high pass filter untuk melemahkan gelombang $\mathrm{P}$ dan $\mathrm{T}$, serta low pass filter untuk menghilangkan noise. Beberapa algoritma lain juga 


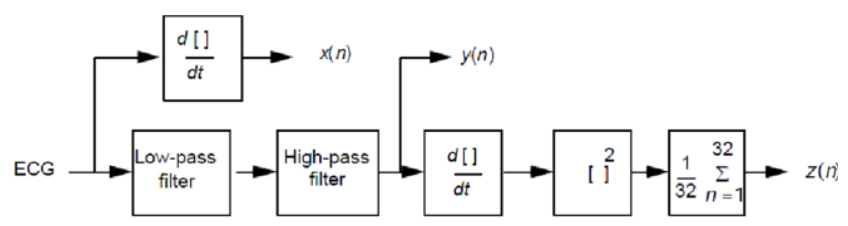

Gambar 4. Algoritma Detektor QRS Oleh Pan Tompkins

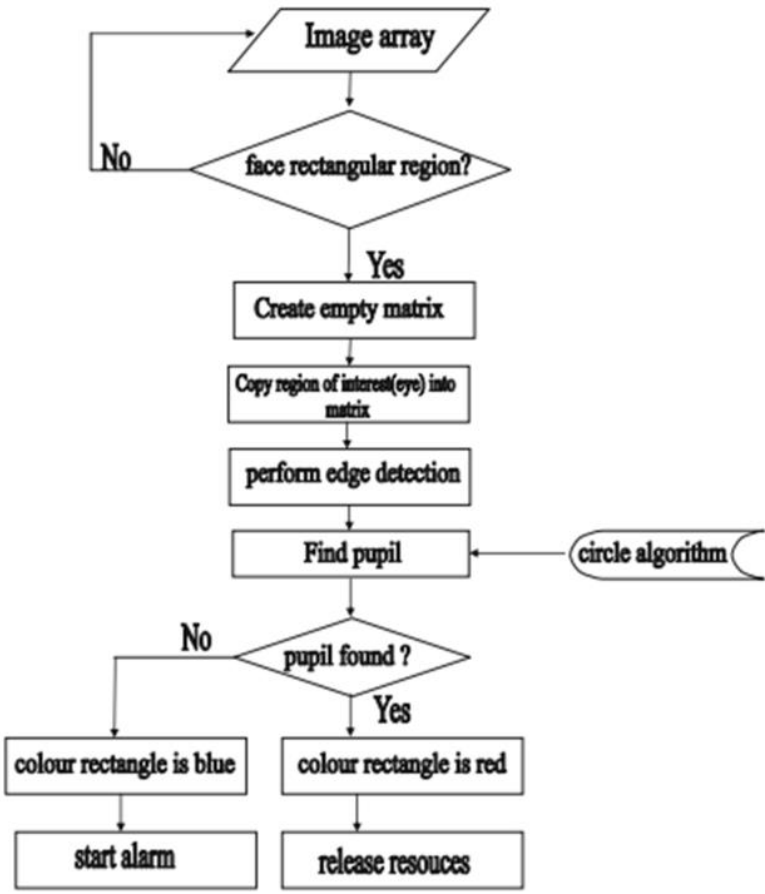

Gambar 5. Algoritma Eye Detection

menggunakan band pass filter untuk mendapatkan sinyal yang lebih baik. Sinyal yang telah difilter kemudian digunakan untuk mendapatkan kompleks QRS dengan cara membandingkannya dengan suatu nilai threshold yang tetap. Algoritma deteksi QRS dapat dilihat pada Gambar 4.

\section{G. Algoritma Viola Jones}

Metode Viola Jones merupakan metode pendeteksian obyek yang memiliki tingkat keakuratan yang cukup tinggi yaitu sekitar 93,7 \%. Metode ini, diusulkan oleh Paul Viola dan Michael Jones pada tahun 2001. Metode Viola Jones menggabungkan empat kunci utama yaitu haar like feature, integral image, adaboost learning dan cascade classifier. Haar like feature yaitu selisih dari jumlah piksel dari daerah di dalam persegi panjang. Nilai Haar like feature diperoleh dari selisih jumlah nilai piksel daerah gelap dengan jumlah nilai piksel daerah terang. Diagram blok algoritma viola jones untuk mendeteksi mata dapat dilihat pada Gambar 5.

\section{H. If then rules}

Algoritma if then rules digunakan untuk mengintegrasikan kedua modalitas. Input yang digunakan yaitu kondisi pengemudi dari masing-masing modalitas. Output yang dihasilkan yaitu kondisi dari pengemudi. If then rule yang digunakan pada sistem dapat dilihat pada Tabel 1 .

\section{HASIL DAN DISKUSI}

\section{A. Pengujian Penguat Instrumentasi}

Pengujian meliputi pengujian penguatan pada IC AD620. Uji penguatan bertujuan untuk membandingkan penguatan
Tabel 1.

If Then Rules Untuk Klasifikasi Kondisi Pengemudi

\begin{tabular}{ccc}
\hline \hline Klasifikasi & Klasifikasi Haar & Kondisi Klasifikasi \\
EKG & Classifier & Pengemudi \\
\hline Normal & Normal & Normal \\
Normal & Kantuk & Normal \\
Kantuk & Normal & Kantuk \\
Kantuk & Kantuk & Kantuk \\
\hline \hline
\end{tabular}

\section{Respon Filter HPF}

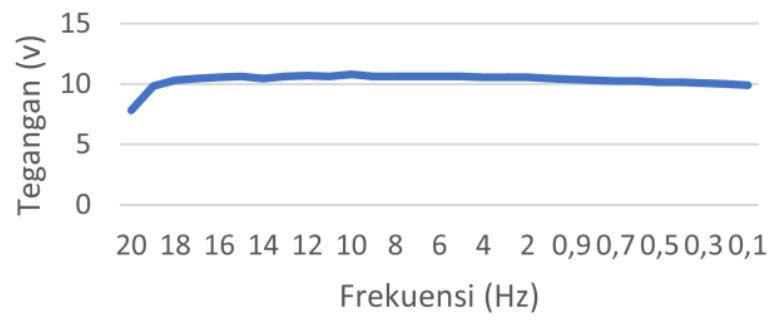

\section{Respon Filter LPF}

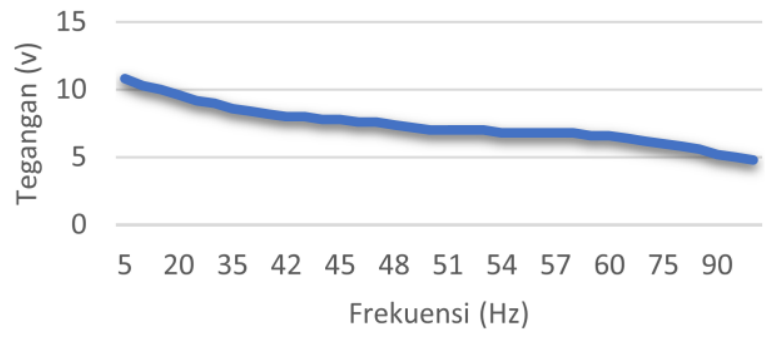

Gambar 6. Konfigurasi Elektroda EKG

secara teroritis dengan saat pengukuran berlangsung. Percobaan dilakukan saat $R_{G}=500 \Omega$. Pengujian dilakukan dengan pengaturan $V_{\text {in }}=10 \mathrm{mV}$. Nilai $V_{\text {out }}=960 \mathrm{mV}$ sehingga,

$G=\frac{49,4 k \Omega}{500 \Omega}+1=99,8$ kali $($ Teori)

$G=\frac{V_{0}}{V_{i}}=\frac{960}{10}=96 k a l i \quad$ (Pengujian)

\section{B. Pengujian Filter}

Filter yang digunakan meliputi low pass filter dan high pass filter. Sinyal input berupa sinyal sinus dengan amplitudo $1 \mathrm{~V}$ dengan variasi berupa frekuensi. Hasil pengujian filter ditunjukkan pada Gambar 6.

\section{Pengujian Baseline Restoration}

Pengujian baseline restoration dilakukan dengan menentukan batas atas dan batas bawah dari masing-masing op amp. Batas atas diatur pada angka $+2 \mathrm{~V}$ dan batas bawah pada $-2 \mathrm{~V}$. Hasil pengujian menunjukkan bahwa saat tegangan input berada dibawah $-2 \mathrm{~V}$, maka $L E D$ akan on dan membuat kapasitor discharge lebih cepat dan membuat sinyal kembali ke baseline. Kemudian saat tegangan berada diatas $+2 \mathrm{~V}$, LED akan kebali $O N$ dan membuat kapasitor discharge lebih cepat dan sinyal kembali ke baseline. Hasil pengujian rangkaian baseline restoration dapat dilihat pada Tabel 2 . 
Tabel 2.

Pengujian Baseline Restoration

\begin{tabular}{cc}
\hline \hline Tegangan Input $(\mathrm{V})$ & Kondisi LED \\
\hline-4 & ON \\
-3 & ON \\
-2 & OFF \\
-1 & OFF \\
0 & OFF \\
1 & OFF \\
2 & OFF \\
3 & ON \\
4 & ON \\
\hline \hline
\end{tabular}

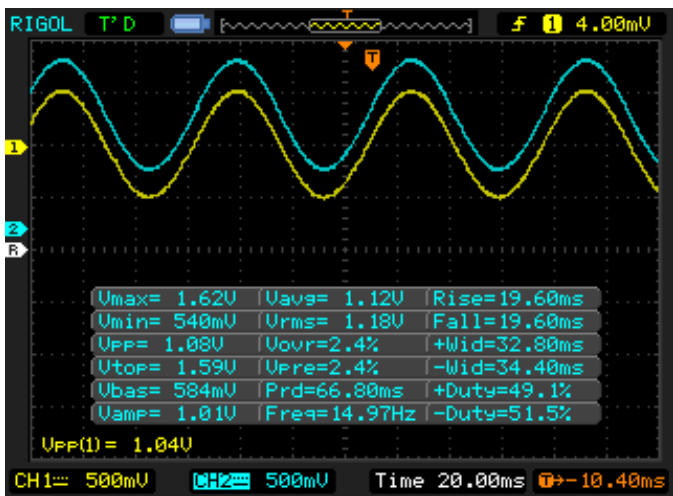

Gambar 7. Pengujian Rangkaian Non Inverting Adder

\section{Pengujian Non Inverting Adder}

Penambahan rangkaian adder bertujuan menaikkan level tegangan sinyal agar dapat dibaca oleh mikrokontroler. Pengujian dilakukan dengan input sinyal sinus dengan amplitude 1V. Dari hasil pengujian didapatkan output sebesar $1,08 \mathrm{~V}$ dengan nilai $V_{\max }=1,62 \mathrm{~V}$. Sehingga tegangan dinaikkan sebanyak $0,62 \mathrm{~V}$ ke atas. Dapat dilihat pada Gambar 7 hasil pengujian non inverting adder.

\section{E. Pengujian Instrumentasi Elektrokardiogram}

Pengujian keseluruhan sistem instrumentasi elektrokardiogram meliputi semua bagian signal processing yaitu penguat instrumentasi, low pass filter, high pass filter, baseline restoration, dan non inverting adder. Pengujian dilakukan dengan kondisi subjek dengan menggunakan elektroda permukaan yang diletakkan dengan titik sadapan left arm (LA) dan right arm (RA) pada bagian dada. Ilustrasi pemasangan elektroda pada subjek dapat dilihat pada Gambar 8 Pengujian dilakukan pada lima subjek. Hasil pengujian pada dua subjek dapat dilihat pada Gambar 9.

Pengujian selanjutnya yaitu untuk menguji algoritma $Q R S$ detection untuk mendapatkan heartrate dan mendapatkan nilai dari rasio LF/HF. Guna mengklasifikasikan kondisi pengemudi menggunakan nilai threshold rasio LF/HF yang digunakan sebesar 0,17 pada kondisi kantuk berdasarkan penelitian sebelumnya [5]. Pengujian dilakukan dengan merekam aktifitas jantung selama dua menit secara kontinu. Hasil pengujian algortima QRS detection untuk mendapatkan heartrate dan rasio LF/HF ditunjukkan pada Tabel 3. Berdasarkan hasil pengujian yang didapatkan dari total lima pengujian tidak ada subjek yang berada dalam kondisi kantuk. Namun, pada saat dilakukan pengujian dilakukan pengkondisian pada subjek 1 dan subjek 2. Pengkondisian yang dilakukan yaitu saat dilakukan pengukuran kedua

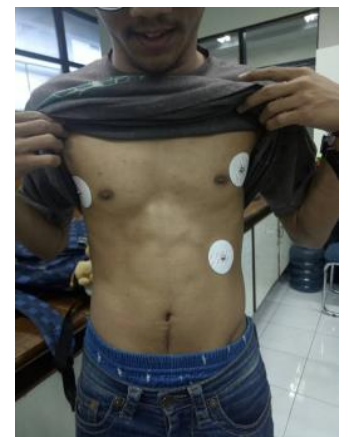

Gambar 8. Ilustrasi Penempatan Elektroda Pada Dada

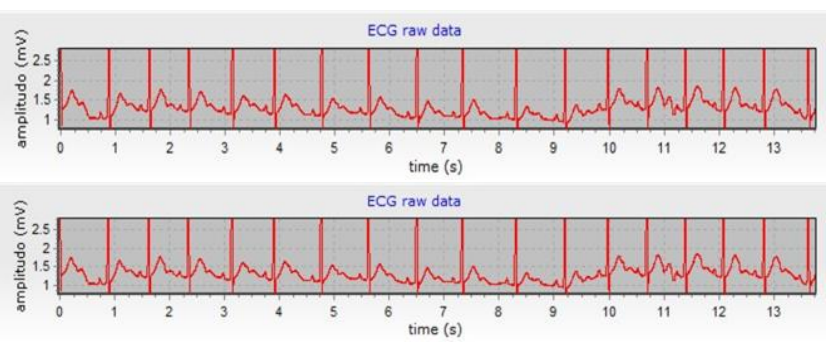

Gambar 9. Sinyal EKG Dari Sadapan Pada Dada Pada Subjek 1 (Atas) Dan Subjek 5 (Bawah)

Tabel 3.

Hasil Pengujian QRS Detection Untuk Mendapatkan Heartrate dan Rasio LF/HF

\begin{tabular}{ccc}
\hline \hline Subjek & Heart Rate & Rasio LF/HF \\
\hline 1 & 84,44 & 0,253 \\
2 & 60,55 & 0,246 \\
3 & 67,48 & 0,320 \\
4 & 79,08 & 0,323 \\
5 & 84,40 & 0,311 \\
\hline \hline
\end{tabular}

subjek pada malam sebelumnya memiliki kualitas tidur yang buruk. Oleh karena itu, sistem seharusnya dapat mendeteksi kantuk pada kedua subjek. Sistem tidak dapat mendeteksi karena nilai dari threshold yang digunakan tidak tercapai.

Namun, jika dilihat dari trend yang didapatkan dari total lima subjek yang diuji. Kedua subjek yang memiliki kualitas tidur yang buruk pada malam sebelumnya pada saat dilakukan pengukuran memiliki nilai rasio $\mathrm{LF} / \mathrm{HF}$ yang cenderung sama dan lebih kecil dari ketiga subjek lainnya. Berdasarkan hasil tersebut maka didapatkan bahwa range rasio LF/HF untuk mengklasifikasikan kondisi kantuk pada pengemudi khususnya untuk pengemudi di Indonesia sebesar $0,17-0,24$.

\section{F. Pengujian Visual Haar Classifier}

Pengujian selanjutnya untuk menguji modalitas kedua yaitu metode visual haar classifier. Pengujian dilakukan dengan menguji sistem untuk mendeteksi area wajah dan mata pada empat subjek dengan penampilan pada tiap subjek yang berbeda-beda. Hasil pengujian sistem untuk mendeteksi area wajah dan mata dapat dilihat pada Tabel 4. Berdasarkan pengujian dari lima pengujian nilai keberhasilan sistem untuk mendeteksi area wajah dan mata sebesar $80 \%$.

Pengujian sistem untuk klasifikasi kondisi dari pengemudi menggunakan nilai threshold dari besarnya eyelid pada data frame pertama. Pengujian dilakukan selama dua menit secara kontinu. Klasifikasi kondisi kantuk terjadi pada saat data frame ke-n lebih kecil dari nilai threshold.

Pada pengujian klasifikasi kondisi dilakukan pengujian pada lima subjek. Hasil pembacaan pada tiap data frame selama dua menit akan dirata-rata. Hasil rata-rata tersebut 
Tabel 4.

Hasil Pengujian QRS Detection Untuk Mendapatkan Heartrate dan Rasio LF/HF

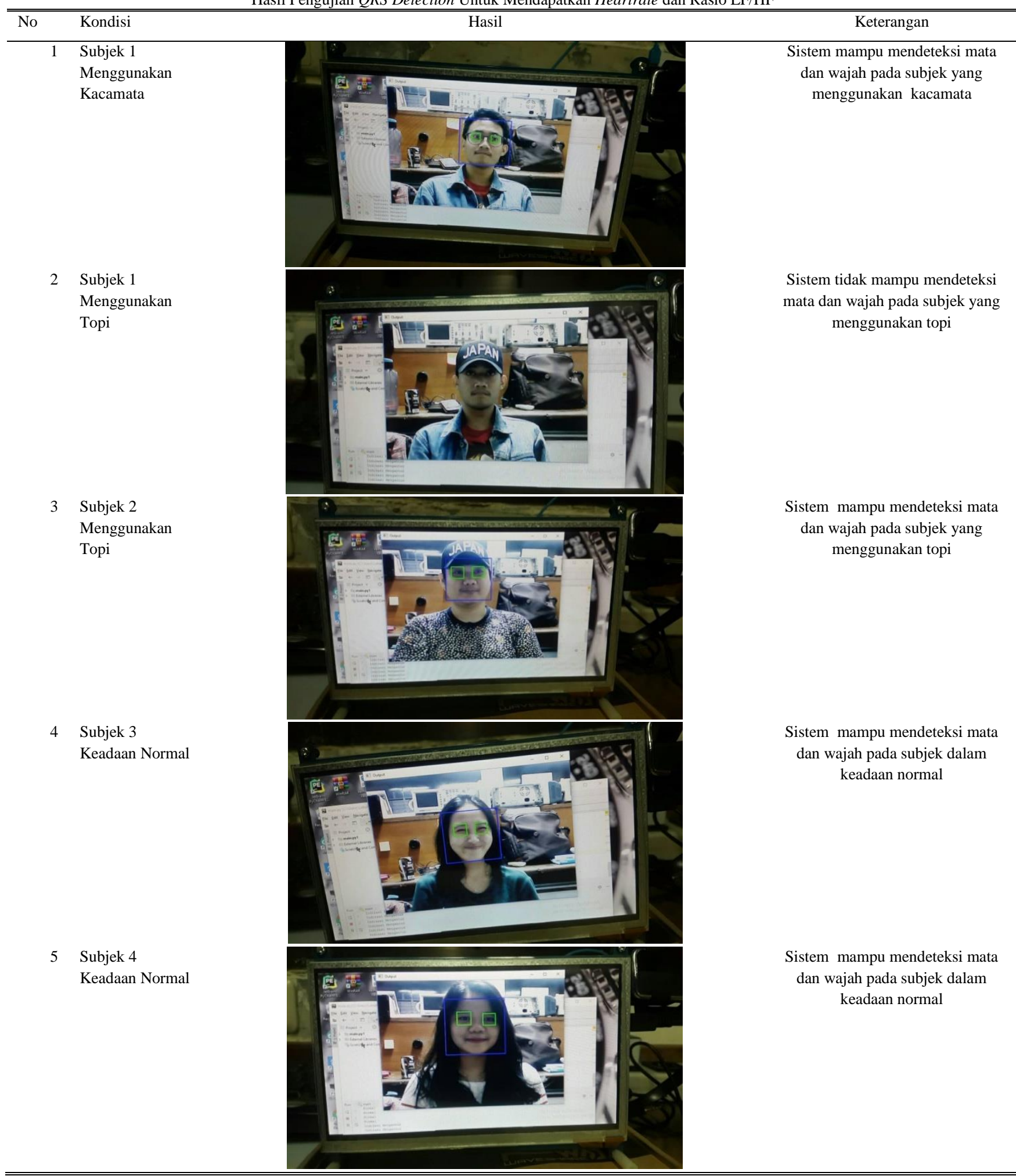

menjadi kondisi dari pengemudi. Hasil pengujian dapat dilihat pada Tabel 5. Sistem mendeteksi dua subjek (subjek 1 dan subjek 4) berada dalam kondisi kantuk. Berdasarkan pengkondisian subjek seharusnya sistem mengklasifikasikan subjek 1 dan subjek 2 berada dalam kondisi kantuk.

\section{G. Pengujian Sistem Klasifikasi Pengemudi}

Pengujian sistem integrasi antara dua modalitas dengan menggunakan metode if then rule. Hasil pengujian sistem integrasi dari kedua sistem dapat dilihat pada Tabel 6.

\section{RINGKASAN DAN KESIMPULAN}

\section{A. Kesimpulan}

Pada penelitian tugas akhir yang menggunakan dua modalitas yaitu instrumentasi elektrokardiogram dan visual menggunakan metode haar cascade untuk memantau kantuk dari pengemudi mobil merupakan penelitian yang tergolong baru dengan menggunakan dua modalitas untuk dapat mengklasifikasikan kondisi dari pengemudi sangat mungkin dilakukan. EKG mampu menangkap sinyal jantung terutama QRS complex dengan jelas, kemudian sinyal masuk kedalam 
Tabel 5.

Pengujian Visual Haar Classifier Untuk Mendeteksi Kantuk

\begin{tabular}{|c|c|c|c|}
\hline No & Kondisi & Data Frame Pertama & Keterangan \\
\hline 1 & Subjek 1 & & $\begin{array}{c}\text { Sistem mengklasifikasikan subjek berada } \\
\text { dalam kondisi kantuk }\end{array}$ \\
\hline 2 & Subjek 2 & & $\begin{array}{c}\text { Sistem mengklasifikasikan subjek berada } \\
\text { dalam kondisi normal }\end{array}$ \\
\hline 3 & Subjek 3 & & $\begin{array}{l}\text { Sistem mengklasifikasikan subjek berada } \\
\text { dalam kondisi normal }\end{array}$ \\
\hline 4 & Subjek 4 & & $\begin{array}{c}\text { Sistem mengklasifikasikan subjek berada } \\
\text { dalam kondisi kantuk }\end{array}$ \\
\hline 5 & Subjek 5 & & $\begin{array}{c}\text { Sistem mengklasifikasikan subjek berada } \\
\text { dalam kondisi normal }\end{array}$ \\
\hline
\end{tabular}

rangkaian penguat instrumentasi dan filter untuk mendapatkan sinyal EKG. Frekuensi cut-off pada filter LPF dan HPF berada pada $50 \mathrm{~Hz}$ dan $0.05 \mathrm{~Hz}$. Baseline restoration digunakan untuk memperbaiki baseline dari sinyal namun sifatnya opsional karena sinyal yang diperoleh sudah berada pada baseline-nya. Kemudian sinyal yang sudah difilter akan diolah untuk dideteksi dengan menggunakan QRS detection untuk memperoleh informasi kondisi dari pengemudi. Hasil yang didapatkan pada klasifikasi keadaan pengemudi dengan menggunakan rasio LF/HF hanya berhasil mendeteksi satu dari tiga subjek yang diuji. Tetapi hal tersebut sangat terpengaruh dari nilai besaran threshold yang ditentukan. Berdasarkan nilai threshold yang digunakaan dalam penelitian ini didapatkan hasil pengujian pada subjek 1 dan subjek 2 memiliki nilai rasio LF/HF yang cenderung sama dengan nilai rata-rata 0,24 . Berdasarkan hasil yang didapat terjadi hasil yang kontras pada subjek 3, subjek 4, dan subjek 5 yang memiliki nilai rasio LF/HF sebesar 0,3 . Jika dilihat dari keadaan sebenarnya pada saat dilakukan pengujian subjek 1 dan subjek 2 berada dalam kondisi yang sama 
Tabel 6.

Hasil Klasifikasi Keadaan Pengemudi

\begin{tabular}{|c|c|c|c|c|c|c|}
\hline Subjek & Heart Rate & Rasio LF/HF & Klasifikasi EKG & Klasifikasi Haar Cascade & Kondisi Klasifikasi Pengemudi & Kondisi Sebenarnya \\
\hline 1 & 84,44 & 0,253 & Normal & Kantuk & Normal & Kantuk \\
\hline 2 & 60,55 & 0,246 & Normal & Normal & Normal & Kantuk \\
\hline 3 & 67,48 & 0,320 & Normal & Normal & Normal & Normal \\
\hline 4 & 79,08 & 0,323 & Normal & Kantuk & Normal & Normal \\
\hline 5 & 84,40 & 0,311 & Normal & Normal & Normal & Normal \\
\hline
\end{tabular}

(kantuk) dan subjek 3, subjek 4, dan subjek 5 berada dalam kondisi normal. Dapat dilihat bahwa rasio LF/HF pada subjek dalam keadaan kantuk memiliki nilai rasio yang lebih rendah daripada subjek dalam keadaan normal. Berdasarkan hasil dari penelitian ini dan penelitian sebelumnya maka didapatkan nilai rasio LF/HF dari kondisi kantuk berada dalam range 0,17-0,24.

Pada sistem visual dengan menggunakan metode haar cascade. Data gambar yang berasal dari kamera akan menjadi input bagi sistem untuk dideteksi area dari wajah dan mata dengan menggunakan data frame hasil training dengan menggunakan metode haar cascade. Kemudian sistem akan mengambil threshold berupa tinggi kelopak mata yang berasal dari pengambilan gambar pertama untuk dibandingkan dengan keadaan tinggi kelopak mata terkini. Sehingga, dengan membandingkan nilai threshold maka sistem dapat mengklasifikasikan kondisi dari pengemudi. Dari hasil pengujian didapatkan nilai keberhasilan sistem yang mampu mendeteksi area wajah dan mata dari subjek sebesar $80 \%$. Berdasarkan hasil yang didapatkan hasil pengklasifikasian dari subjek bergantung dari nilai keberhasilan sistem untuk mendeteksi wajah dan mata. Hal tersebut didukung dengan keberhasilan sistem yang mampu mengklasifikasikan kondisi subjek. Sisi penampilan dari pengemudi sangat berpengaruh terhadap sistem deteksi, contohnya seperti penggunaan kacamata dan topi dapat menambah faktor kegagalan deteksi wajah dan mata.

Secara keseluruhan sistem integrasi dari kedua modalitas dapat bekerja dengan baik untuk mengklasifikasikan kondisi pengemudi. Tetapi nilai keberhasilan dari sistem masih rendah. Hal ini dikarenakan metode pengklasifikasian menggunakan nilai threshold yang statis. Selain itu sisi penampilan dari pengemudi berpengaruh dalam pengklasifikasian. Rendahnya nilai keberhasilan yang diperoleh disebabkan metode pengklasifikasian menggunakan metode if then rule yang cenderung statis (crisp), tidak memiliki batasan yang lebih luas. Sehingga sistem tidak memiliki nilai toleransi yang tinggi (fuzzy).

\section{B. Saran}

Saran untuk pengembangan selanjutnya adalah mendesain alat EKG yang lebih compact, dan menggunakan rangkaian baseline restoration yang lebih baik agar sinyal yang dihasilkan lebih tahan terhadap guncangan atau gerakan dari pengemudi. Penggunaan metode integrasi sebaikanya menggunakan metode yang adaptif sehingga tidak statis.

\section{DAFTAR PUSTAKA}

[1] Badan Pusat Statistik, "Tabel Dinamis: Perkembangan Jumlah Kendaraan Bermotor Menurut Jenis," 2017. [Online]. Available: https://www.bps.go.id/linkTableDinamis/view/id/1133. [Accessed: 02Nov-2018].

[2] Polisi Lalu Lintas, "Polantas Dalam Angka Tahun 2013," 2013. [Online]. Available: http://korlantas.polri.go.id/wpcontent/uploads/2015/10/PolantasDalamAngka2013.pdf. [Accessed: 02-Nov-2018].

[3] E. Abe, K. Fujiwara, T. Hiraoka, T. Yamakawa, and M. Kano, "Development of drowsiness detection method by integrating heart rate variability analysis and multivariate statistical process control," SICE J. Control. Meas. Syst. Integr., vol. 9, no. 1, pp. 10-17, 2016.

[4] L. F. Ibrahim et al., "Using Haar classifiers to detect driver fatigue and provide alerts," Multimed. Tools Appl., vol. 71, no. 3, pp. 1857-1877, 2014

[5] K.-W. Ke, M. R. Zulman, H.-T. Wu, Y.-F. Huang, and J. Thiagarajan, "Drowsiness detection system using heartbeat rate in android-based handheld devices," in 2016 First International Conference on Multimedia and Image Processing (ICMIP), 2016, pp. 99-103. 